\title{
Multiplex Enrichment and Detection of Rare KRAS Mutations in Liquid Biopsy Samples using Digital Droplet Pre-Amplification
}

\author{
Erica D. Pratt ${ }^{1^{*}}$, Robert W. Cowan ${ }^{1}$, Sara L. Manning ${ }^{1}$, Edmund Qiao ${ }^{2}$, Heather Cameron ${ }^{3}$, \\ Kara Schradle ${ }^{3}$, Diane Simeone ${ }^{3}$, David B. Zhen ${ }^{\dagger 2}$ \\ ${ }^{1}$ Ahmed Center for Pancreatic Cancer Research, Department of Gastroenterology, Hepatology \\ and Nutrition, University of Texas MD Anderson Cancer Center, Houston, TX, ${ }^{2}$ Division of \\ Gastroenterology, Department of Internal Medicine, University of Michigan, Ann Arbor, MI, ${ }^{3}$ \\ Division of Hepatobiliary Surgery, Department of Surgery Comprehensive Cancer Center, \\ University of Michigan, Ann Arbor, MI
}

Correspondence:

Erica D. Pratt

University of Minnesota Twin Cities

420 Washington Ave SE

MCB 7-194

Minnesota, MN 55455

pratte@umn.edu 


\section{Abstract}

Oncology research is increasingly incorporating molecular detection of circulating tumor DNA (ctDNA) as a tool for cancer surveillance and early detection. However, non-invasive monitoring of conditions with low tumor burden remains challenging, as the diagnostic sensitivity of most ctDNA assays is inversely correlated with total DNA concentration and ctDNA abundance. Here we present the Multiplex Enrichment using Droplet Pre-Amplification (MED-Amp) method, which com-bines single-molecule emulsification and short-round PCR preamplification with digital droplet PCR (ddPCR) detection of mutant DNA template. The MED-Amp assay increased mutant signal by over 50 -fold with minimal distortion in allelic frequency. We demonstrate detection of as few as 3 mutant copies in wild-type DNA concentrations ranging from 5 to 50 ng. The MED-Amp assay successfully detected KRAS mutant ctDNA in 86\% plasma samples obtained from patients with met-astatic pancreatic ductal adenocarcinoma. This assay for highsensitivity rare variant detection is appropriate for liquid biopsy samples, or other limited clinical biospecimens 


\section{Introduction}

Prior research has shown that digital droplet PCR (ddPCR) has superior accuracy to traditional quantitative PCR (qPCR) for detection of rare genetic mutations. ddPCR also outperforms qPCR in biological fluids containing natural PCR inhibitors ${ }^{1}$, more accurately distinguishes between rare events and false-positives ${ }^{2}$, and minimizes measurement variation by partitioning DNA template into thousands to millions of discrete reaction volumes. Each droplet becomes an individual PCR reaction event, increasing target signal-to-noise ratio, and theoretically enabling detection of mutations with allelic frequencies lower than $0.1 \%$. Due to its sensitivity and cost-effectiveness, ddPCR is an attractive alternative to next-generation sequencing for targeted detection of rare mutations. Thus, ddPCR is increasingly used in cancer research for high-sensitivity molecular detection of circulating tumor DNA (ctDNA) for non-invasive detection and monitoring of disease.

Circulating tumor DNA is released into the circulation from tumor cells and is a non-invasive prognostic indicator of survival ${ }^{3}$. However, the majority of cell-free DNA (cfDNA) in the circulation is wild-type and may contain as little as one mutant DNA fragment per milliliter of plasma ${ }^{3,4,5}$. Prior work has demonstrated ddPCR is a powerful tool for ctDNA detection and serial monitoring for patients with advanced disease and high tumor burden ${ }^{6,7}$. However, diagnostic sensitivity is inversely correlated with total cfDNA concentration, limiting detection in samples where either wild-type or mutant DNA concentrations are low $5,8,9$, such as serial monitoring of minimal residual disease. An especially salient example is pancreatic cancer, where over $90 \%$ of primary tumors contain a KRAS mutation ${ }^{10}$. Yet in recent studies of patients with confirmed KRAS mutant positive tumors, only $35-43 \%$ of plasma samples also tested positive via ddPCR ${ }^{5,11}$.

To further increase assay sensitivity for detection of low DNA input and low target abundance samples, several groups have performed short cycles of conventional PCR with a high-fidelity polymerase to increase the starting concentration of nucleic acids prior to downstream detection. A recent study showed that preamplification of template increased true-positive ddPCR signal 
from 15- to 27 -fold with only nine cycles of PCR with only a 1.5- to 9-fold increase in false positives. This preamplification method enabled detection of $0.05 \%$ mutant $K R A S$ ctDNA in $50 \mathrm{ng}$ of wild-type DNA ${ }^{12}$. Furthermore, multiplexed detection of cancer-specific mutations was possible with total cfDNA inputs as low as $9 \mathrm{ng}$. Similarly, fifteen cycles of preamplification prior to nextgeneration sequencing resulted in detection of mutant transcripts at $0.63 \%$ allelic frequency with DNA inputs as low as $2 \mathrm{ng}^{13}$. However, conventional PCR is sensitive to amplification bias based on DNA fragment size, resulting in distortion of the original allelic fraction. Circulating tumor DNA is highly fragmented, exists at very low concentrations, and is systematically shorter than wildtype cfDNA ${ }^{14}$, making it particularly susceptible to these biases. Additionally, prior research has shown a $10-20 \%$ reduction in PCR amplification efficiency for mutation-containing DNA fragments in common tumor-specific genes, such as TP53 and KRAS ${ }^{15}$.

Here we describe a new assay, Multiplex Ennrichment using ㅁoplet Pre-Amplification (MEDAmp), which addresses the limitations described above. This method combines single-molecule DNA emulsification in picoliter volume droplets with nine rounds of preamplification using a highfidelity polymerase, followed by ddPCR detection of template. The MED-Amp assay has the capacity to identify single mutant DNA fragments from wild-type using cfDNA inputs as low as 5 ng. We show that the MED-Amp method generates linear DNA template amplification, enabling back-calculation of original ctDNA concentrations. Finally, we piloted our assay with plasma samples from patients with metastatic pancreatic ductal adenocarcinoma (PDA) for multiplexed detection of the four most common KRAS codon 12 mutations in pancreatic cancer (p.G12C, p.G12D, p.G12R, p.G12V) ${ }^{10}$.

\section{Results}

Multiplex KRAS mutation targeting. Our multiplex mutation detection method consisted of DNA template emulsification and PCR amplification in droplets prior to de-emulsification and 
repartitioning for analysis using standard TaqMan® ${ }^{\circledR}$ chemistry (Figure 1). In our assay, DNA template and high-fidelity polymerase master mix were loaded on the RainDance Source digital PCR system for single-molecule partitioning in 5 picoliter volume droplets. After nine rounds of PCR amplification, the resulting PCR product was de-emulsified, purified, and repartitioned with TaqMan ${ }^{\circ}$ Genotyping Master Mix combined with TaqMan® probes for KRAS detection.

We designed a multiplexed KRAS panel, combining TaqMan® probes targeting wild-type sequence, and the most common KRAS codon 12 mutations in PDA (p.G12C, p.G12D, p.G12R, p.G12V) ${ }^{10}$. Based on biorepository data (ICGC, QCMG, and TCGA) encompassing over 700 patients, these four KRAS mutations are present in $84 \%$ of PDA samples. Previous studies have shown ctDNA is heavily fragmented, averaging 160 bp in length ${ }^{14,16}$. Therefore, we designed a KRAS primer set producing a $95 \mathrm{bp}$ amplicon flanking the codon 12 mutation sites of interest (SI Table 1). To maximize assay sensitivity, a FAM reporter was used for all four KRAS mutant probes and concentrations were optimized such that all FAM-positive events clustered into a single gate. FAM-positive events would then achieve maximum separation from the much stronger wild-type VIC signal. We confirmed successful probe multiplexing into a single G12 mutation gate (labeled G12*) using a mixture of DNA from various pancreatic cell lines encompassing all four KRAS mutations (data not shown).

Detection of mutant alleles using droplet-based preamplification. To recapitulate circulating tumor DNA concentrations seen in plasma samples, we created twelve artificial dilutions of a KRAS gene-specific multiplex reference standard containing a characterized KRAS p.G12D mutation at $16.7 \%$ allelic frequency. Dilutions were created by mixing the reference standard with DNA from the BxPC3 human PDA cell line, which is homozygous for wild-type KRAS at codon 12. KRAS mutant copy number ranged from 3 to 272 in a total wild-type background of 1,426 to 14,257 (5- 
50ng) genomic equivalents, resulting in allelic frequencies spanning $0.02 \%$ to $8.71 \%$. Each allelic frequency was replicated at least fourteen times.

We successfully identified KRAS p.G12D mutations in $87 \%$ of samples tested (Figure 2a). There was high concordance between measured KRAS mutant fraction post-preamplification and nominal expected fraction across the allelic frequencies tested (Figure 2b). Post-preamplification FAM signal was linearly correlated with input mutant DNA copy number as described by a generalized least squares regression model with an exponential variance function to correct for heteroscedasticity $(p<0.001)$. The linearity of amplification across a two order-of-magnitude change in mutant template copy number allows for straightforward back-calculation of original sample VAF.

To assess overall assay performance, we then compared the number of mutant KRAS droplets detected via ddPCR with and without preamplification. Amplification ratio, defined as number of KRAS mutant droplets measured by ddPCR divided by number of spiked KRAS mutant copies, was used to characterize preamplification efficiency. Each allelic frequency tested was assayed in triplicate. Emulsified preamplification increased mutant KRAS signal an average of 50 -fold with only an 8-fold increase in false positives from non-template or wild-type KRAS controls (Figure 3a \& 3b), consistent with other preamplification-based techniques ${ }^{12}$. While preamplification resulted in a mean 50 -fold increase in signal, this falls well short of the over 500 -fold increase expected from nine cycles of preamplification. These data are consistent with prior reports of suppressed amplification using a variety of high-fidelity polymerases for preamplification ${ }^{12,}{ }^{13}$. Amplification was uniform across a two order of magnitude change in mutant KRAS copy number and allelic fraction (Figure 3c). However, unlike other preamplification protocols ${ }^{8,9}$, MED-Amp 
had no dependence on total DNA input (SI Table 2). These data show emulsified preamplification may improve the sensitivity of detection of variant alleles at extremely low concentrations.

Droplet preamplification improves variant allele detection compared to conventional PCR preamplification. We also compared droplet- versus conventional-PCR preamplification (Figure 4). Overall amplification ratio was not correlated with template emulsification $(p=0.38)$. However, droplet amplification was two-fold more efficient than conventional amplification as the allelic frequency dropped below $0.2 \%$, near the limit of detection of most ddPCR assays $(p=0.03)$ (Figure 4a). Importantly, conventional preamplification consistently underestimated mutant KRAS template allelic frequency, and was on average 59\% lower than droplet preamplification (Figure 4b \& 4c). Therefore, droplet preamplification was further developed for highly sensitive and specific detection of rare variants.

Evaluation of high-fidelity polymerase performance. We next compared the performance of three commercially available high-fidelity polymerases, Q5® Hot Start High-Fidelity, PfuUltra II Fusion $\mathrm{HS}$, and Platinum ${ }^{\mathrm{TM}}$ SuperFi ${ }^{\mathrm{TM}}$, in our assay. Each polymerase was tested at minimum four types at each mutant DNA copy number assayed. While all three polymerases were effective, Q5® led to a 59-fold increase in detected KRAS signal compared to PfuUltra II Fusion HS (50-fold) and Platinum $^{\mathrm{TM}}$ SuperFi ${ }^{\mathrm{TM}}$ (30-fold) (Figure 5a). This trend remained after normalization for amplification variability by input mutant $K R A S$ copy number. $Q 5 ®$ and PfuUltra II exhibited higher, more variable, signal amplification, while Platinum ${ }^{\mathrm{TM}}$ SuperFi ${ }^{\mathrm{TM}}$ signal amplification was lower and more consistent (Figure 5b). We also compared the limit of detection (LOD) for the three polymerases using our assay. All three polymerases produced minimal false-positives in nontemplate controls: on average seven droplets for Platinum ${ }^{\mathrm{TM}}$ SuperFi ${ }^{\mathrm{TM}}$, ten for $\mathrm{Q} 5 \AA$, and seventeen for PfuUltra II. These data informed limit of detection calculations for each polymerase. We performed a chi-squared goodness-of-fit test and found droplet counts did not fit a Poisson 
distribution as is commonly assumed in analytical sensitivity measurements ${ }^{17,}{ }^{18}$. Therefore, LOD was defined as three standard deviations from the mean false-positive count of each polymerase non-template control ${ }^{18}$. Based on these LOD calculations, Q5®, Platinum ${ }^{\mathrm{TM}}$ SuperFi $\mathrm{i}^{\mathrm{TM}}$ and PfuUltra II detected three mutant KRAS molecules with $75 \%, 70 \%$, and $60 \%$ sensitivity and $100 \%$ specificity, respectively (SI Table 2). Q5® High-Fidelity polymerase was selected for further assay optimization based on its performance in detecting extremely low amounts of KRAS mutations, efficiency in amplification, and specificity.

MED-Amp detection of KRAS mutations in plasma. The genomic standards described previously were spiked into $1 \mathrm{~mL}$ of plasma from donors without cancer, and the DNA was isolated and assayed as described above. Each copy number input was assayed at minimum in triplicate. Overall assay sensitivity in spiked plasma samples was $67.7 \%$ for fewer than 20 mutant DNA copies and $91 \%$ for 20 copies and above. Despite the presence of natural PCR inhibitors in plasma, and losses associated with the DNA isolation process, assay sensitivity remained high and compared favorably to detection rates using DNA reference standards alone (Figure 6a).

MED-Amp detection of KRAS mutations in patient samples. We next applied our assay to PDA patient plasma samples (Figure 6b, Table 1, SI Table 4). We measured KRAS mutations in blinded plasma samples from metastatic PDA patients $(n=7)$, and age-matched non-PDA patient controls $(\mathrm{n}=10)$. Cell-free DNA was isolated from $1-2 \mathrm{~mL}$ of plasma from each patient. Final DNA concentrations ranged from $3 \mathrm{ng} / \mathrm{mL}$ to $49 \mathrm{ng} / \mathrm{mL}$ and were significantly higher in PDA samples compared to controls ( $p<0.001$, SI Figure 2). The maximum template volume of $8 \mu \mathrm{L}$ per $25 \mu \mathrm{L}$ reaction volume was used for each preamplification reaction (1.2 ng to $18 \mathrm{ng}$ total). There was no correlation found between cfDNA concentration and age or sex across groups. Additionally, mutant KRAS detection did not correlate with total DNA input (Figure 6c). This is in contrast to 
prior reports where KRAS variant detection was correlated with higher DNA input, which does not itself necessarily correlate with disease activity ${ }^{5,9}$.

KRAS codon 12 mutations were identified in 6 out of 7 PDA patient samples tested (Figure $6 \mathrm{~b}$ $\& 6 d)$, resulting in a diagnostic sensitivity of $86 \%$. Three out of ten control samples also tested positive for mutant $K R A S$, yielding a specificity of $70 \%$. Samples positive for the mutation had no correlation with age for either cohort. Measured allelic frequencies were highly heterogeneous in patient samples, ranging from $0.04 \%$ to $13.4 \%$. The average mutant allelic frequency was much higher in PDA samples (3.89\%) compared to controls (1.43\%, $p=0.33$ ) (SI Figure 2). Based on input DNA concentrations, the total number of mutant DNA fragments present in the tested plasma samples ranged from 1.56 to 195 copies.

We then examined the controls samples which tested KRAS-positive. Controls with sufficient remaining plasma, or isolated cfDNA, were re-analyzed using standard ddPCR, and the presence of codon 12 KRAS mutations was confirmed (SI Figure 3). Two controls were censored after review of patient records revealed a prior history of cancer, one of which tested mutant KRAS positive by MED-Amp. Of the remaining eight patients, six had a history of colorectal polyps. Prior research has identified KRAS codon 12 mutations in $15-38 \%$ of patients with polyps ${ }^{19}$. Recent studies have also reported similar false-positive rates in patients with no history of cancer $20,21,22$, 23, 24, 25. These findings suggest somatic KRAS mutations may also be a marker of neoplasia or other premalignant conditions.

\section{Conclusion}

Current ddPCR-based genotyping studies have three major limitations: 1) a strong interdependence between total DNA input and assay sensitivity $5,8,9,2$ ) low rates of ctDNA detection as compared to matched tumor tissue specimens ${ }^{3,4,5}$, and 3) misestimation of ctDNA allelic frequency. cfDNA input in the sub-5 ng range is a disqualifying factor for commercial digital sequencing assays ${ }^{26}$. In contrast, by using a droplet preamplification step with a high-fidelity 
polymerase, the MED-Amp method accurately detects low abundance mutations in sub-5 ng DNA input samples. Preamplification in droplets may be a critical step, as Barnard and colleagues reported a strong PCR bias against point mutations within CXGG motifs in KRAS codon 12, as well as TP53 codons 248 and 282, when co-amplified with wild-type sequence ${ }^{15}$. These data corroborate our observation that conventional PCR preamplification underestimates mutant KRAS allelic frequency. Barnard et al. found the observed PCR bias was abated by amplifying wild-type and mutant template in separate reactions, which is analogous to partitioning DNA molecules into individual droplets to serve as compartmentalized PCR reaction vessels. Hence, the emulsification of template prior to PCR leads to more efficient template amplification than conventional PCR preamplification, while also preserving the allelic distribution of the original DNA sample.

The high efficiency of mutant template amplification could explain our reported $86 \% K R A S$ ctDNA detection rate, which is comparable to methods employing more expensive nextgeneration sequencing. In contrast, only $35 \%$ to $64.7 \%$ of late-stage metastatic patients tested positive in other ddPCR-based assays ${ }^{4,27,28}$. Further validation in a larger patient cohort is needed, but our pilot data suggest droplet preamplification could achieve results similar to NGSbased methods and performed at less cost (approximately $\$ 200$ per sample).

Interestingly, we found that $30 \%$ of controls tested positive for KRAS mutations. There is a growing body of showing KRAS and other tumor biomarkers are present at low levels in individuals with no evidence of malignant disease. These observations have been seen in cfDNA and exosomal DNA, at rates ranging from $5 \%-20 \%$, consistent with the results reported here ${ }^{19}$, $21,23,25,22,24$. The preponderance of studies reporting similar rates of oncogenic mutations using various detection methods, genetic targets, and ranges of DNA inputs suggests further investigation into the prevalence of these mutations in aging populations is warranted. Furthermore, the majority of control samples are obtained at single-time points, and the lack of 
serial blood draws for analysis limits the ability to determine if the above results represent actual false-positives or early detection of malignant conditions.

While this study focused exclusively on PDA, the method described here could be applied to other tumor types and biospecimens including fine needle aspirates ${ }^{29}$, as well as archived FFPE or frozen tissue samples. Assay sensitivity remained high, even when applied to frozen samples under extended storage conditions (> 2 years), enabling retrospective analysis of stored samples. Furthermore, MED-Amp can be integrated with existing assays, such as mutation detection in circulating tumor cells ${ }^{30}$ and next-generation sequencing of samples with limited DNA ${ }^{13}$. These qualities make MED-Amp a potentially versatile tool that could be easily integrated into clinical studies.

\section{Materials \& Methods \\ Reagents and Materials}

Horizon KRAS Gene-Specific Multiplex Reference Standard (Catalog ID HD780, Horizon Discovery), Qiagen MiniElute PCR Purification (Cat. No. 28004, Qiagen), Q5® Hot Start HighFidelity (Catalog \# M0494S, New England BioLabs ${ }^{\circ}$ Inc.), PfuUltra II Fusion HS (Catalog \# 600670, Agilent Technologies), Platinum ${ }^{\mathrm{TM}}$ SuperFi $^{\mathrm{TM}}$ (ThermoFisher Scientific), UltraPure ${ }^{\mathrm{TM}}$ DNase/RNase-Free distilled water (Cat. No. 10977023, ThermoFisher Scientific), TaqMan® Genotyping Master Mix (Cat. No. 4371355, ThermoFisher Scientific)

\section{Preparation of KRAS genomic standards for assay benchmarking}

Genomic standards were created with controlled mutant KRAS content by diluting Horizon KRAS Gene-Specific Multiplex Reference Standard with BxPC3 cell line genomic DNA. Standards were made to cover allelic frequencies ranging from $10.33 \%$ to $0.02 \%$ and total DNA content ranging from $50 \mathrm{ng}$ to $5 \mathrm{ng}$. Standards were prepared in UltraPure ${ }^{\mathrm{TM}}$ DNase/RNase-Free distilled water.

\section{Preamplification using ddPCR}

A maximum of $8 \mu \mathrm{L}$ of DNA template was used for PCR reactions using one of three high-fidelity polymerases: Q5® Hot Start High-Fidelity, PfuUltra II Fusion HS, and Platinum ${ }^{\mathrm{TM}}$ SuperFi ${ }^{\mathrm{TM}}$. The RainDance Source digital PCR system was used to partition the reaction mix into approximately 5 million droplets, each five picoliters in volume (Figure 1). PCR strips containing emulsified droplets were run in a thermocycler for 9 cycles of preamplification (PCR protocols available in Supplementary Information). The droplet suspension was de-emulsified using droplet destabilizer, and residual carrier oil removed. The PCR product was processed using the Qiagen MiniElute PCR Purification kit as specified, with an additional 5 minute incubation at $35^{\circ} \mathrm{C}$ prior to final spin down. The elution volume for all samples was $10 \mu \mathrm{L}$, and samples were stored at $-20^{\circ} \mathrm{C}$ until further use.

\section{ddPCR detection of preamplified template}

$5 \mu \mathrm{L}$ of each sample was added to $12.5 \mu \mathrm{L}$ of TaqMan Genotyping Master Mix, $0.9 \mu \mathrm{L}$ of $25 \mu \mathrm{M}$ primers, $1 \mu \mathrm{L}$ of droplet stabilizer, $0.15 \mu \mathrm{L}$ of $12.5 \mu \mathrm{M}$ probes for KRAS wild- 
type/G12C/G12D/G12R/G12V (probe sequences available in Supplementary Information), and water to a final volume of $25 \mu \mathrm{L}$. The RainDance Source digital PCR system was used again to partition the reaction mix, and emulsified droplets were processed in a thermocycler with a $10 \mathrm{~min}$ annealing step at $95^{\circ} \mathrm{C}$, followed by 45 cycles of $95^{\circ} \mathrm{C}$ for $15 \mathrm{~s}$ and $60^{\circ} \mathrm{C}$ for $1 \mathrm{~min}$, concluding with a $10 \mathrm{~min}$ extension at $98^{\circ} \mathrm{C}$. Droplets were processed using the RainDance Sense digital PCR system, and resulting populations were gated using RainDance Analyst II ${ }^{\mathrm{TM}}$ software.

\section{Patient Characteristics}

Seventeen plasma samples were collected after Institutional Review Board approval (HUM25339) at University of Michigan and under compliance with HIPPA guidelines. Ten samples were collected from patients undergoing routine colonoscopy. Seven samples were collected from metastatic PDA patients. Eight patients were female, nine male. The average age was 54 for healthy controls and 66 for PDA patients (Table 1). Two patients had prior, or ongoing, chemotherapy and radiation treatment.

\section{Patient plasma collection}

Patient blood samples were drawn in either Streck or EDTA tubes and were processed within 30 minutes of collection. Samples were centrifuged for 10 minutes at $820 \mathrm{xg}$ at $4^{\circ} \mathrm{C}$. The plasma supernatant was extracted via pipette and aliquoted in $1 \mathrm{~mL}$ volumes in $1.5 \mathrm{~mL}$ Eppendorf tubes. Plasma samples underwent a second spin at $16,000 \mathrm{xg}$ for 10 minutes at $4^{\circ} \mathrm{C}$. Samples were stored at $-80^{\circ} \mathrm{C}$ until further processing. Matching buffy coat was also collected and stored at $80^{\circ} \mathrm{C}$.

\section{Patient plasma isolation}

$200 \mu \mathrm{L}$ of Proteinase $\mathrm{K}$ was added to all plasma samples, which were then processed using the QIAmp ${ }^{\circledR}$ Circulating Nucleic Acid kit as specified. Purified DNA samples were eluted in $150 \mu \mathrm{L}$ Buffer AVE (RNase-free water with $0.04 \%$ sodium azide) and stored at $-80^{\circ} \mathrm{C}$ until further use. Samples were concentrated using a standard ethanol precipitation protocol. Briefly, $0.1 \mathrm{vol}$ of sodium acetate, $2.5 \mathrm{vol}$ of $100 \%$ ethanol, and $0.06 \mu \mathrm{g} / \mu \mathrm{L}$ of glycogen was added to each DNA aliquot and stored overnight at $-80^{\circ} \mathrm{C}$. Aliquots were centrifuged at $12,000 \mathrm{x} \mathrm{g}$ at $4^{\circ} \mathrm{C}$ for $30 \mathrm{~min}$. The supernatant was decanted and the pellet was rinsed once with ice cold $70 \%$ ethanol. The supernatant was decanted, and samples were left to air dry before resuspension in $10 \mu \mathrm{L}$ of UltraPure $^{\text {TM }}$ DNAase/RNAase-free distilled water. Samples were quantified using the Qubit ${ }^{\text {TM }} 3.0$ Fluorometer High Sensitivity Kit. Final sample DNA concentrations ranged from 0.16 to $2.3 \mathrm{ng} / \mu \mathrm{L}$.

\section{Statistical analysis}

Wilcoxon rank-sum or Kruskal-Wallis tests were used to compare differences between groups. The Conover test with holm p-value correction was used for posthoc analysis. Data analysis was performed using $\mathrm{R} 3.4 .4$, a multi-platform open-source language and software for statistical computing ${ }^{31}$.

\section{ASSOCIATED CONTENT}

\section{Supporting Information}

Supplementary tables \& figures (pdf)

SI Table 1 KRAS primer and probe sequences.

SI Table 2 Sensitivity measurements for each high-fidelity polymerase tested by input KRAS copy number and total allelic frequency. 
SI Table 3 Sensitivity measurement for plasma spike samples for each allelic frequency tested.

SI Table 4 Patient Characteristics

SI Figure 1 Representative MED-Amp results for non-template controls for each of the high-fidelity polymerases tested.

SI Figure 2 Mean cell-free DNA concentration in non-PDA controls versus metastatic PDA samples. Measured allelic frequency for controls and PDA patient samples.

SI Figure 3 Confirmation of KRAS mutant signal in non-PDA controls S01, and S03 via ddPCR.

\section{AUTHOR INFORMATION}

\section{Corresponding Author}

${ }^{*}$ Erica D. Pratt

University of Minnesota Twin Cities

420 Washington Ave SE

MCB 7-194

Minnesota, MN 55455

pratte@umn.edu

\section{Present Addresses}

† Division of Medical Oncology, Department of Internal Medicine, University of Washington, Seattle, WA

\section{Author Contributions}

EDP designed and performed experiments, analyzed data and wrote the manuscript. DBZ designed and performed experiments, analyzed data, and identified patients for study recruitment. RWC designed and performed experiments. EQ performed experiments. SLM performed experiments, consented, and collected patient samples. HC, and KS consented and collected patient samples. DS provided patient specimens.

\section{ACKNOWLEDGMENT}

This study was financially supported by the National Institutes of Health (CA177857; DK088945; CA016672), Doris Duke Clinical Scholar Award, CPRIT Rising Stars Award (RR160022), Andrew Sabin Family Foundation, MDACC Physician Scientist Program, and the UT Stars Award. EDP and DBZ were partially supported by an NIH T32 Training Grant (T32 CA 9676-22) through the University of Michigan Cancer Biology Program.

\section{REFERENCES}

(1) Taylor, S. C.; Laperriere, G.; Germain, H. Sci Rep-Uk 2017, 7.

(2) Hindson, C. M.; Chevillet, J. R.; Briggs, H. A.; Gallichotte, E. N.; Ruf, I. K.; Hindson, B. J.; Vessella, R. L.; Tewari, M. Nature methods 2013, $10,1003-+$.

(3) Pietrasz, D.; Pécuchet, N.; Garlan, F.; Didelot, A.; Dubreuil, O.; Doat, S.; Imbert-Bismut, F.; Karoui, M.; Vaillant, J.-C.; Taly, V.; LaurentPuig, P.; Bachet, J.-B. Clinical Cancer Research 2016.

(4) Takai, E.; Totoki, Y.; Nakamura, H.; Morizane, C.; Nara, S.; Hama, N.; Suzuki, M.; Furukawa, E.; Kato, M.; Hayashi, H.; Kohno, T.; Ueno, H.; Shimada, K.; Okusaka, T.; Nakagama, H.; Shibata, T.; Yachida, S. Sci Rep-Uk 2015, 5.

(5) Brychta, N.; Krahn, T.; von Ahsenh, O. Clinical chemistry 2016, 62, 1482-1491.

(6) Olsson, E.; Winter, C.; George, A.; Chen, Y. L.; Howlin, J.; Tang, M. H. E.; Dahlgren, M.; Schulz, R.; Grabau, D.; van Westen, D.; Ferno, M.; Ingvar, C.; Rose, C.; Bendahl, P. O.; Ryden, L.; Borg, A.; Gruvberger-Saal, S. K.; Jernstrom, H.; Saal, L. H. Embo Mol Med 2015, 7, $1034-1047$.

(7) Sundaresan, T. K.; Sequist, L. V.; Heymach, J. V.; Riely, G. J.; Janne, P. A.; Koch, W. H.; Sullivan, J. P.; Fox, D. B.; Maher, R.; Muzikansky, A.; Webb, A.; Tran, H. T.; Giri, U.; Fleisher, M.; Yu, H. A.; Wei, W.; Johnson, B. E.; Barber, T. A.; Walsh, J. R.; Engelman, J. A., et al. Clinical cancer research : an official journal of the American Association for Cancer Research 2016, 22, 1103-1110.

(8) Oxnard, G. R.; Paweletz, C. P.; Kuang, Y. A.; Mach, S. L.; O'Connell, A.; Messineo, M. M.; Luke, J. J.; Butaney, M.; Kirschmeier, P.; Jackman, D. M.; Janne, P. A. Clinical Cancer Research 2014, 20, 1698-1705. 
bioRxiv preprint doi: https://doi.org/10.1101/298299; this version posted April 24, 2019. The copyright holder for this preprint (which was not certified by peer review) is the author/funder. All rights reserved. No reuse allowed without permission.

(9) Zhang, Y.; Xu, Y.; Zhong, W.; Zhao, J.; Chen, M. J.; Zhang, L.; Li, L. Y.; Wang, M. Z. Oncotarget 2017, 8, 5861-5873.

(10) Pellegata, N. S.; Sessa, F.; Renault, B.; Bonato, M.; Leone, B. E.; Solcia, E.; Ranzani, G. N. Cancer research 1994, 54, $1556-1560$.

(11) Sausen, M.; Phallen, J.; Adleff, V.; Jones, S.; Leary, R. J.; Barrett, M. T.; Anagnostou, V.; Parpart-Li, S.; Murphy, D.; Li, Q. K.; Hruban, C. A.; Scharpf, R.; White, J. R.; O'Dwyer, P. J.; Allen, P. J.; Eshleman, J. R.; Thompson, C. B.; Klimstra, D. S.; Linehan, D. C.; Maitra, A., et al. Nature Communications 2015, 6.

(12) Jackson, J. B.; Choi, D. S.; Luketich, J. D.; Pennathur, A.; Stahlberg, A.; Godfrey, T. E. Journal of Molecular Diagnostics 2016, 18, $235-243$.

(13) Guan, Y.; Mayba, O.; Sandmann, T.; Lu, S.; Choi, Y.; Darbonne, W. C.; Leveque, V.; Ryner, L.; Humke, E.; Tam, N. W. R.; Sujathasarma, S.; Cheung, A.; Richard, B.; Lackner, M. R.; Wang, Y. The Journal of Molecular Diagnostics 2017.

(14) Underhill, H. R.; Kitzman, J. O.; Hellwig, S.; Welker, N. C.; Daza, R.; Baker, D. N.; Gligorich, K. M.; Rostomily, R. C.; Bronner, M. P.; Shendure, J. PLoS genetics 2016, 12.

(15) Barnard, R.; Futo, V.; Pecheniuk, N.; Slattery, M.; Walsh, T. BioTechniques 1998, 25, 684-+.

(16) Mouliere, F.; Robert, B.; Peyrotte, E. A.; Del Rio, M.; Ychou, M.; Molina, F.; Gongora, C.; Thierry, A. R. PloS one 2011, 6.

(17) Milbury, C. A.; Zhong, Q.; Lin, J.; Williams, M.; Olson, J.; Link, D. R.; Hutchison, B. Biomolecular Detection and Quantification 2014, 1, 822.

(18) Armbruster, D. A.; Pry, T. The Clinical Biochemist Reviews 2008, 29, S49-S52.

(19) Kopreski, M. S.; Benko, F. A.; Borys, D. J.; Khan, A.; McGarrity, T. J.; Gocke, C. D. J Natl Cancer I 2000, 92, 918-923.

(20) San Lucas, F. A.; Allenson, K.; Bernard, V.; Castillo, J.; Kim, D. U.; Ellis, K.; Ehli, E. A.; Davies, G. E.; Petersen, J. L.; Li, D.; Wolff, R.; Katz, M.; Varadhachary, G.; Wistuba, I.; Maitra, A.; Alvarez, H. Ann Oncol 2016, 27, 635-641.

(21) Krimmel, J. D.; Schmitt, M. W.; Harrell, M. I.; Agnew, K. J.; Kennedy, S. R.; Emond, M. J.; Loeb, L. A.; Swisher, E. M.; Risques, R. A. Proceedings of the National Academy of Sciences of the United States of America 2016, 113, 6005-6010.

(22) Allenson, K.; Castillo, J.; San Lucas, F. A. S.; Scelo, G.; Kim, D. U.; Bernard, V.; Davis, G.; Kumar, T.; Katz, M.; Overman, M. J.; Foretova, L.; Fabianova, E.; Holcatova, I.; Janout, V.; Meric-Bernstam, F.; Gascoyne, P.; Wistuba, I.; Varadhachary, G.; Brennan, P.; Hanash, S., et al. Ann Oncol 2017, 28, 741-747.

(23) Eshleman, J. R.; Norris, A. L.; Sadakari, Y.; Debeljak, M.; Borges, M.; Harrington, C.; Lin, E.; Brant, A.; Barkley, T.; Almario, J. A.; Topazian, M.; Farrell, J.; Syngal, S.; Lee, J. H.; Yu, J.; Hruban, R. H.; Kanda, M.; Canto, M. I.; Goggins, M. Clin Gastroenterol H 2015, $13,963-U 469$.

(24) Yang, S. J.; Che, S. P. Y.; Kurywchak, P.; Tavormina, J. L.; Gansmo, L. B.; de Sampaio, P. C.; Tachezy, M.; Bockhorn, M.; Gebauer, F.; Haltom, A. R.; Melo, S. A.; LeBleu, V. S.; Kalluri, R. Cancer Biol Ther 2017, 18, 158-165.

(25) Kinugasa, H.; Nouso, K.; Miyahara, K.; Morimoto, Y.; Dohi, C.; Tsutsumi, K.; Kato, H.; Matsubara, T.; Okada, H.; Yamamoto, K. Cancer 2015, 121, 2271-2280.

(26) Lanman, R. B.; Mortimer, S. A.; Zill, O. A.; Sebisanovic, D.; Lopez, R.; Blau, S.; Collisson, E. A.; Divers, S. G.; Hoon, D. S. B.; Kopetz, E. S.; Lee, J.; Nikolinakos, P. G.; Baca, A. M.; Kermani, B. G.; Eltoukhy, H.; Talasaz, A. PloS one 2015, 10.

(27) Bettegowda, C.; Sausen, M.; Leary, R. J.; Kinde, I.; Wang, Y.; Agrawal, N.; Bartlett, B. R.; Wang, H.; Luber, B.; Alani, R. M.; Antonarakis, E. S.; Azad, N. S.; Bardelli, A.; Brem, H.; Cameron, J. L.; Lee, C. C.; Fecher, L. A.; Gallia, G. L.; Gibbs, P.; Le, D., et al. Science translational medicine 2014, 6, 224ra224.

(28) Pietrasz, D.; Pecuchet, N.; Garlan, F.; Didelot, A.; Dubreuil, O.; Doat, S.; Imbert-Bismut, F.; Karoui, M.; Vaillant, J. C.; Taly, V.; LaurentPuig, P.; Bachet, J. B. Clinical cancer research : an official journal of the American Association for Cancer Research 2017, 23, 116-123.

(29) Sho, S. N.; Court, C. M.; Kim, S.; Braxton, D. R.; Hou, S.; Muthusamy, V. R.; Watson, R. R.; Sedarat, A.; Tseng, H. R.; Tomlinson, J. S. PloS one 2017, 12 .

(30) Pratt, E. D.; Stepansky, A.; Hicks, J.; Kirby, B. J. Analytical chemistry 2014, 86, 11013-11017.

(31) Team, R. C. 2013. 


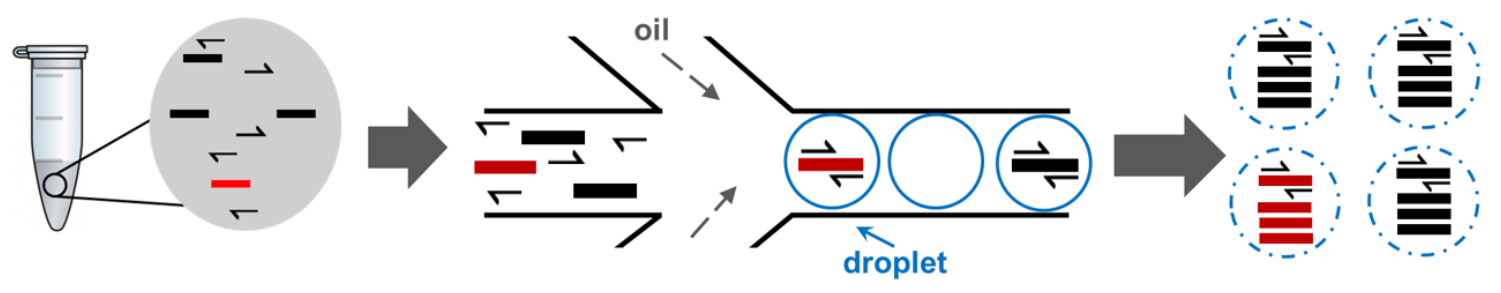

$$
\begin{aligned}
& \text { Primers }-\mathrm{WT} \\
& -\mathrm{MT} \quad \text { Partition sample }
\end{aligned}
$$

preamplification

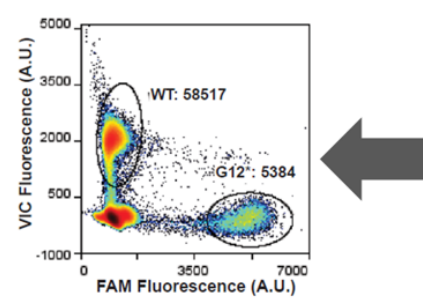

Enumerate fluorescent droplets

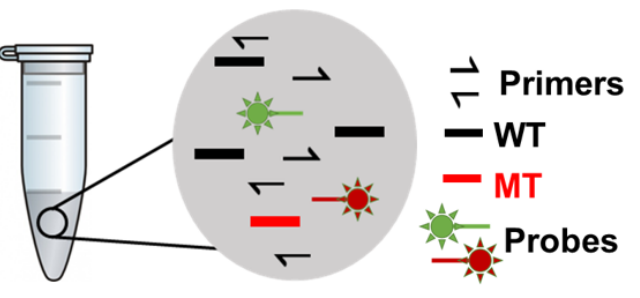

Re-Partition sample + PCR

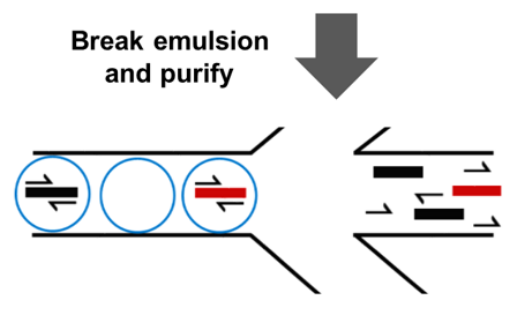

Figure 1. Experimental workflow for MED-Amp. Master mix containing DNA template, primers, and PCR reagents are partitioned into $5 \mathrm{pL}$ droplets and undergo 9 rounds of preamplification. The emulsion is broken and the PCR product is purified using a PCR cleanup kit, then re-partitioned with primers and TaqMan® probes for digital PCR detection. 

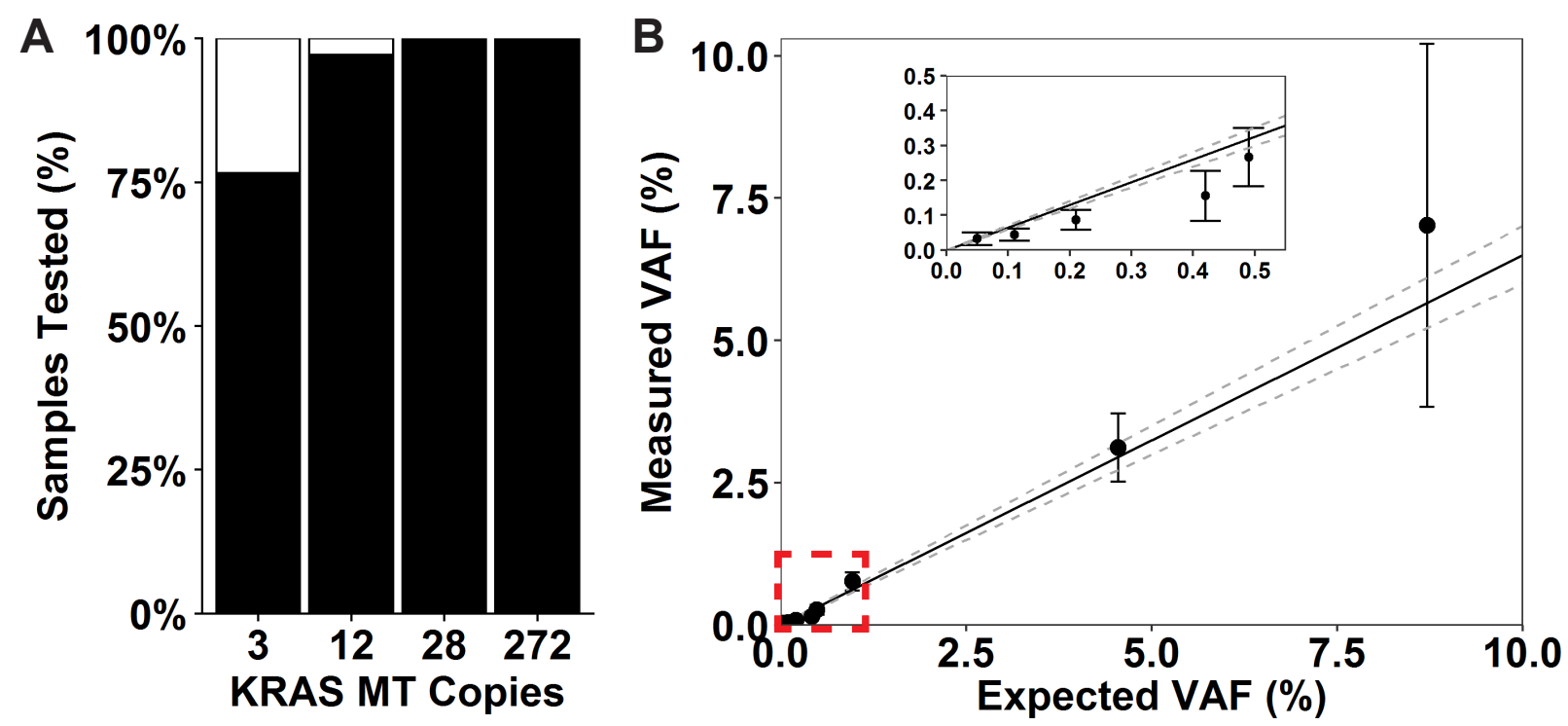

Figure 2. A) MED-Amp detection sensitivity as a function of input mutant KRAS copy number. B) Nominal expected frequency versus measured allelic frequency (VAF). Best fit generated using generalized least squares regression model with heteroscedasticity correction $\left(y=0+0.650^{*} x\right)$. Inset shows $<0.5 \%$ allelic frequency data for clarity. 

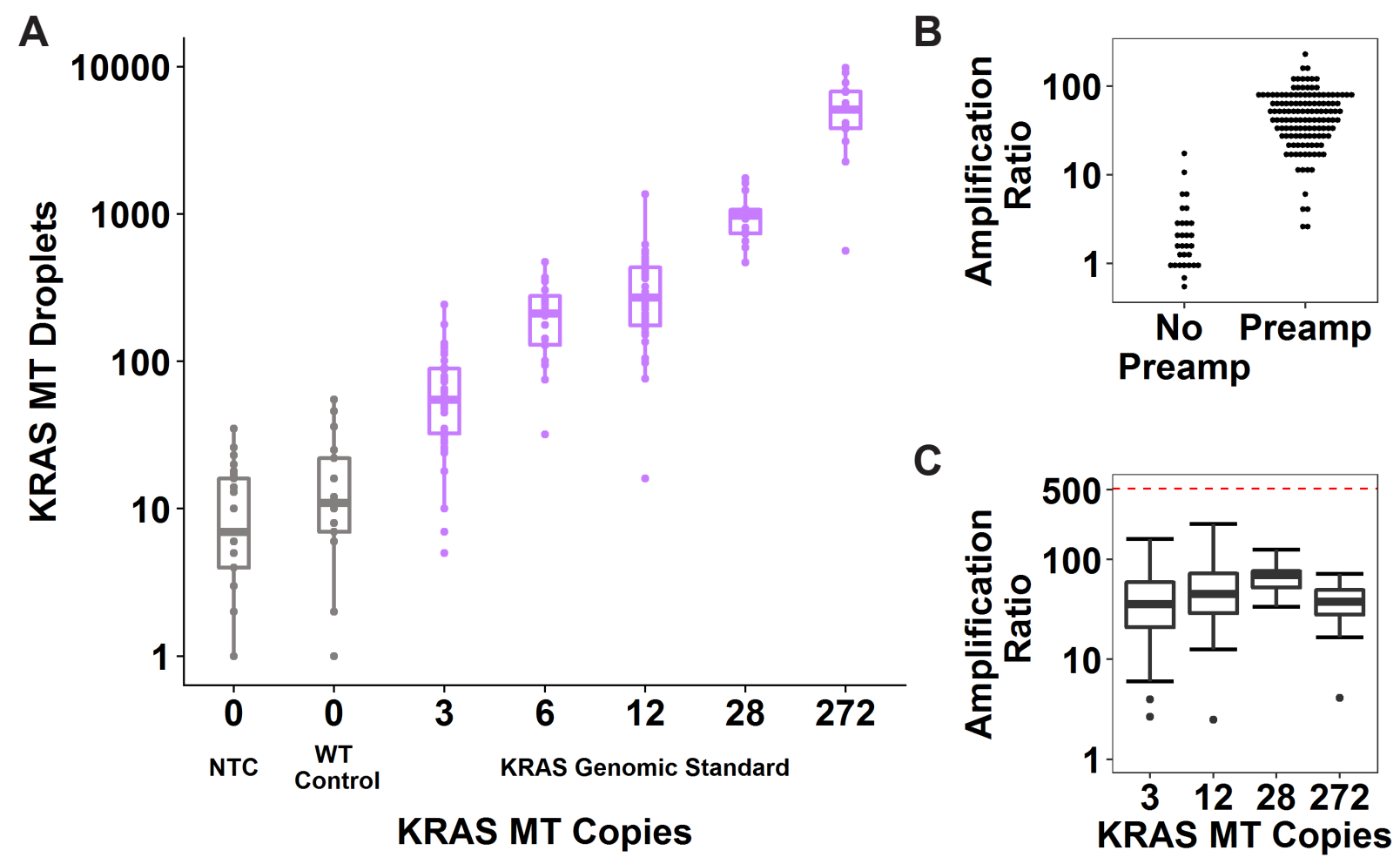

Figure 3. Evaluation of pre-amplification in droplets for detection of KRAS codon 12 mutations. A) Signal amplification as a function of KRAS mutant (MT) copy number. B) Average amplification ratio (defined as KRAS mutant signal divided by number of spiked KRAS mutant copies) of DNA standards containing the KRAS p.G12D mutation with and without preamplification. C) Variation in amplification ratio as a function of number of KRAS mutant copies present in the DNA sample. Dashed line is the expected amplification efficiency for a perfectly efficient PCR reaction. 
A

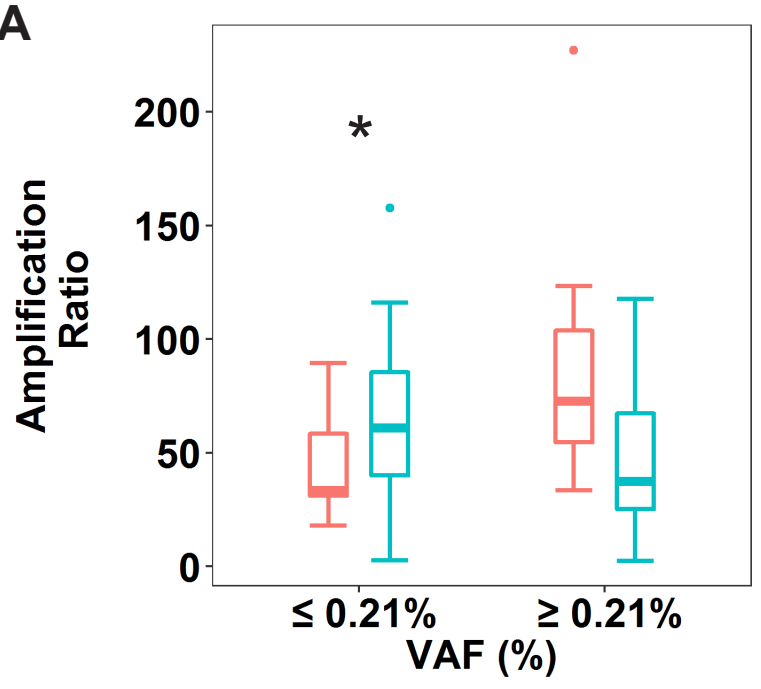

ウ Bulk ウ Droplets
B

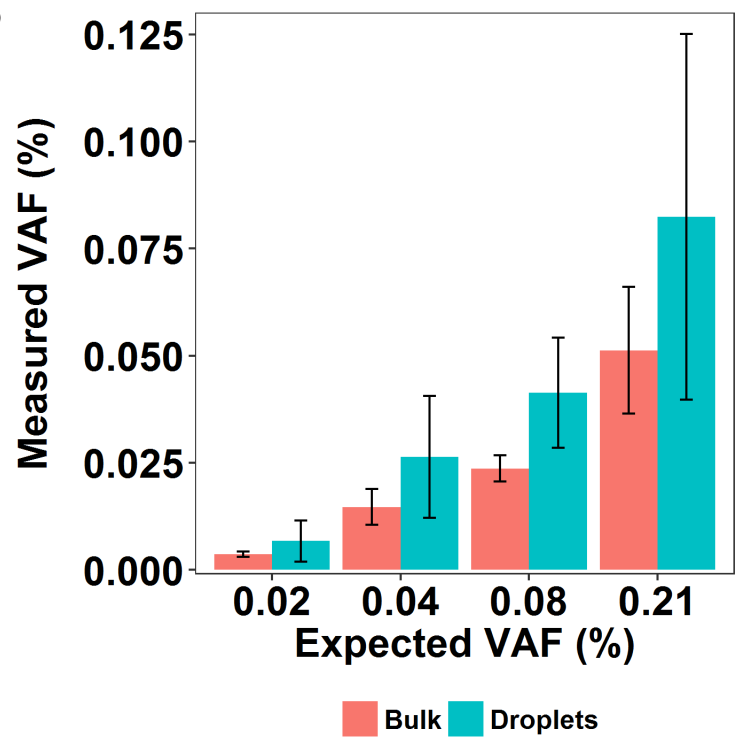

C

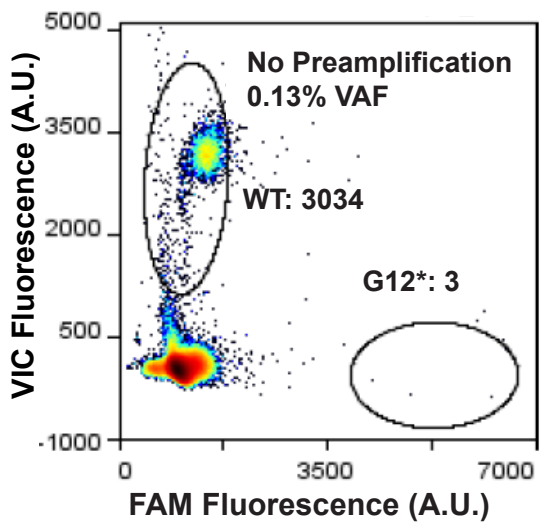

5 ng Wild-Type KRAS DNA

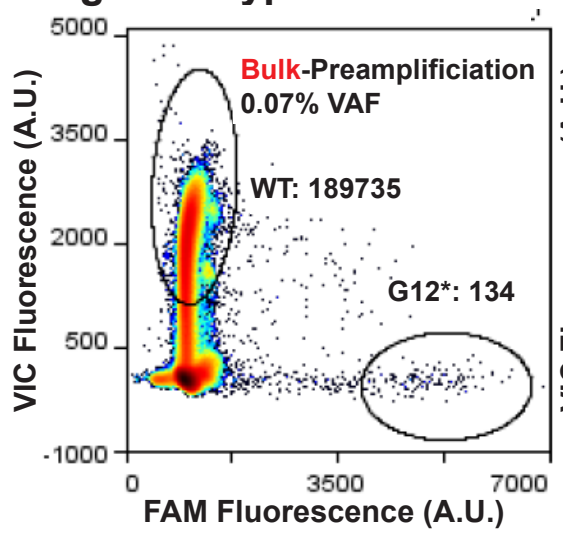

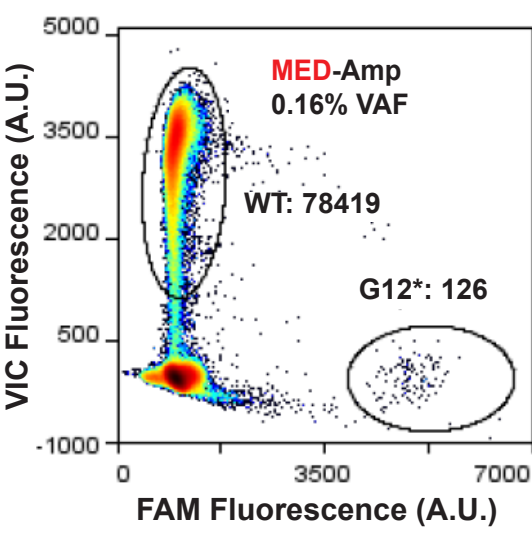

Figure 4. Comparison of ddPCR amplification efficiency and measurement fidelity in bulk preamplification versus MED-Amp. A) Amplification ratio dependence on relative abundance of KRAS mutant DNA. * $p=0.03 \mathrm{~B}$ ) allelic frequency fidelity for bulk preamplification versus preamplification in droplets. C) Representative ddPCR results for each amplification condition versus a non-preamplification control. Fluorescence intensity is measured in arbitrary units (A.U.) 
A

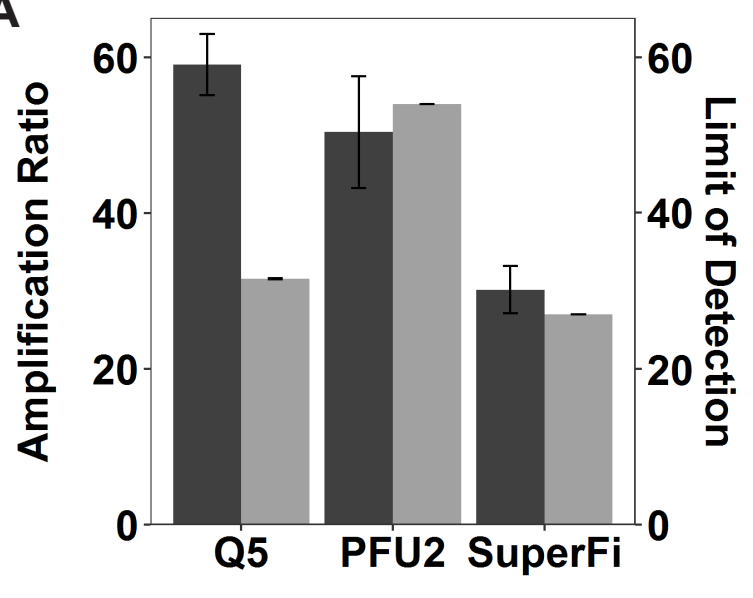

Amplification Ratio Limit of Detection
B

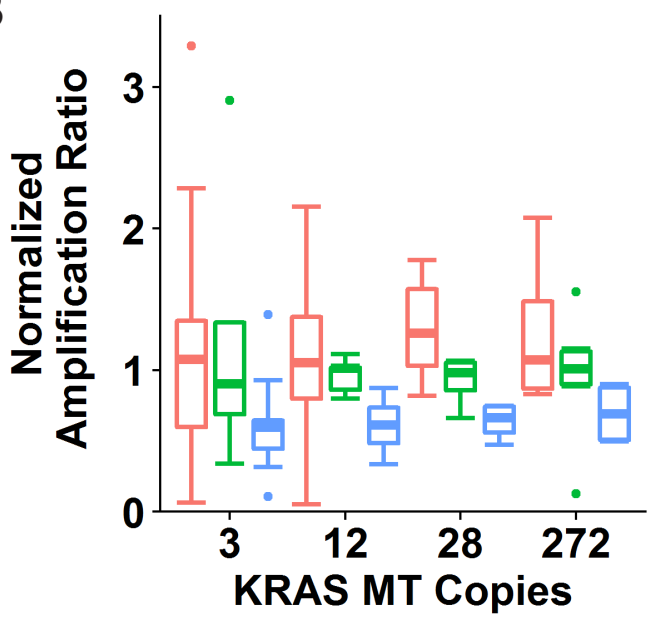

부 Q5 追 PFU2 官 SuperFi

Figure 5. Comparison of High-fidelity polymerases for DNA preamplification. A) Amplification ratio for each high-fidelity polymerase versus its corresponding limit of detection. B) Amplification ratio for each polymerase normalized by mean amplification efficiency per input mutant KRAS copy number. C) 

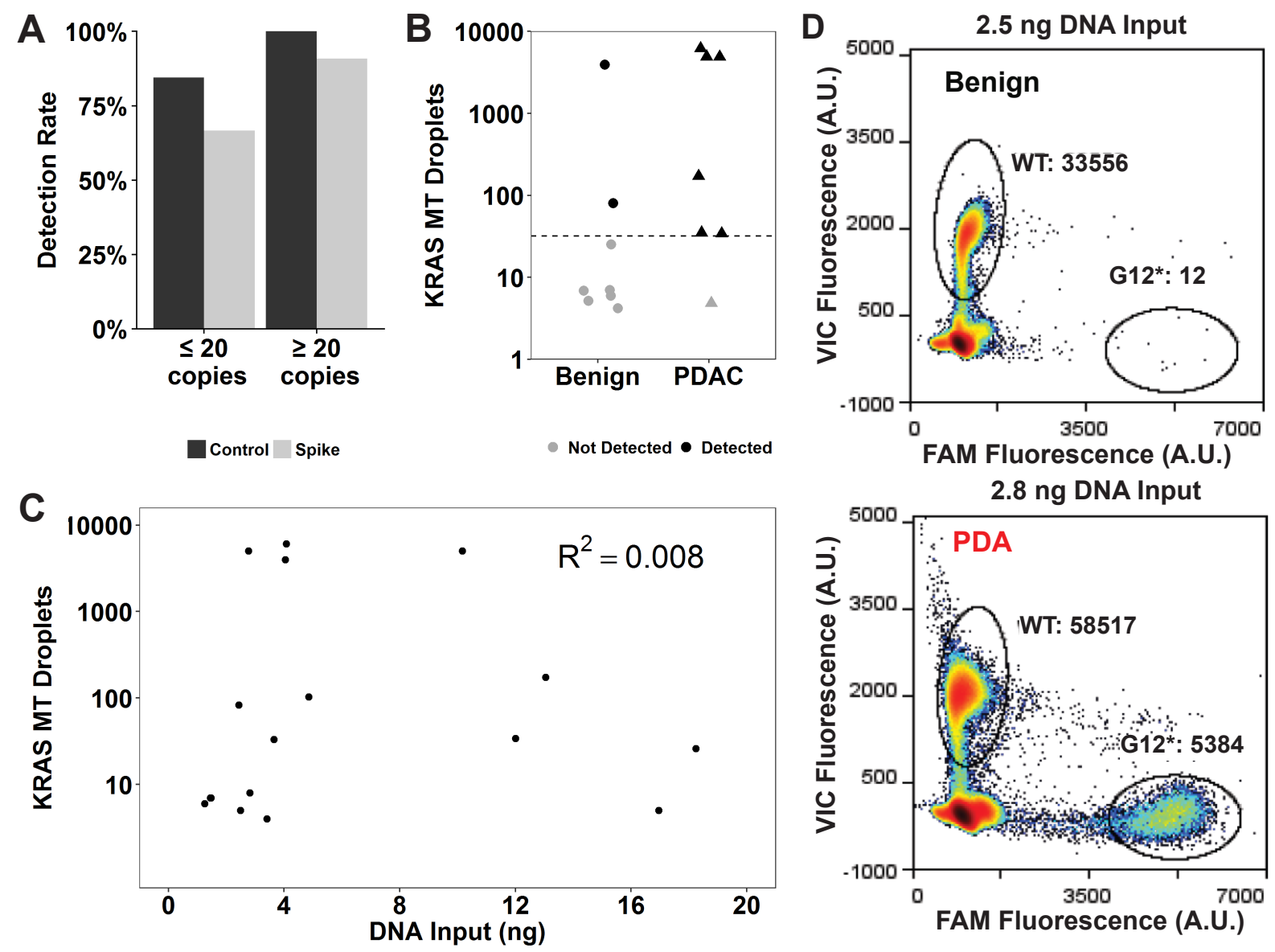

Figure 6. A) MED-Amp detection rate in spiked plasma samples compared to DNA reference standards alone based on input mutant DNA copy number. B) Correlation between ddPCR signal for mutant KRAS and total DNA loaded for the PI-Amp assay. C) Mutant KRAS signal in plasma from metastatic pancreatic cancer patients versus healthy controls. Dashed line indicates the limit of detection (LOD), defined as three standard deviations from the mean false-positive count. D) Representative ddPCR results for low-input DNA samples (<5 ng) for a benign control versus a PDA patient. 


\begin{tabular}{ccccccccccc}
$\begin{array}{c}\text { Sample } \\
\text { ID }\end{array}$ & Age & Sex & Pathology & $\begin{array}{c}\text { Tumor } \\
\text { Location }\end{array}$ & $\begin{array}{c}\text { Tumor Size } \\
(\mathbf{c m})\end{array}$ & $\begin{array}{c}\text { Prior } \\
\text { Therapy }\end{array}$ & $\begin{array}{c}\text { DNA Input } \\
(\mathbf{n g})\end{array}$ & $\begin{array}{c}\text { AF (\%) } \\
\text { Droplets }\end{array}$ & $\begin{array}{c}\text { MT } \\
\text { Droplets }\end{array}$ \\
\hline S03 & 46 & M & Control & -- & - & -- & 4.0 & 13.5 & 25612 & 3989 \\
S04 & 55 & M & Control & -- & -- & -- & 2.4 & 0.03 & 277324 & 83 \\
S05 & 47 & M & Control & -- & -- & -- & 18.2 & 0.20 & 12731 & 23 \\
S06 & 58 & M & Control & -- & -- & -- & 2.5 & 0.01 & 33993 & 5 \\
S07 & 53 & F & Control & -- & -- & -- & 3.4 & 0.01 & 32744 & 4 \\
S08 & 49 & F & Control & -- & -- & -- & 1.5 & 0.15 & 4661 & 7 \\
S09 & 51 & M & Control & -- & -- & -- & 1.2 & 0.06 & 9465 & 6 \\
S10 & 83 & F & Control & -- & -- & -- & 1.4 & 0.05 & 13376 & 7 \\
S11 & 74 & M & PDA & Head & 2.6 & None & 10.2 & 5.4 & 87900 & 5016 \\
S12 & 58 & F & PDA & Body & 8.8 & None & 2.8 & 8 & 57904 & 5023 \\
S13 & 55 & F & PDA & Body/Tail & 5.5 & None & 4.1 & 13.4 & 39260 & 6097 \\
S14 & 75 & F & PDA & Head & 9.1 & None & 17.0 & 0 & 219011 & 5 \\
S15 & 72 & F & PDA & Tail & 5.4 & None & 12.0 & 0.04 & 76245 & 34 \\
S16 & 62 & F & PDA & Head & 3 & Chemotherapy, & 3.6 & 0.24 & 13712 & 33 \\
S17 & 66 & M & PDA & Head & 8 & Radiation & & & \\
\end{tabular}

Table 1. Patient Characteristics

*Shaded rows indicate positive KRAS detection by ddPCR 